\title{
Qualitative Evaluation of Particulate Matter Inside Public Transit Buses Operated by Biodiesel
}

\author{
Kaushik K. Shandilya and Ashok Kumar* \\ Civil Engineering Department, The University of Toledo, Toledo, Ohio 43606, USA
}

\begin{abstract}
The Environmental scanning electron microscopy (ESEM) has been used in a preliminary study to determine the size and morphology of fine particulate matter (PM). This was done with several samples collected inside public transit buses fueled with a 20 percent biodiesel blend of biodiesel and ultra-low sulfur diesel (B20). As the technique is nondestructive, particles of interest can be relocated for further analysis. The practical issue of instrumentation compatibility is addressed. In addition, results showing SEM chemical images from several PM of particle size less than $10 \mu \mathrm{m}\left(\mathrm{PM}_{10}\right)$ samples are reported. Shape analysis suggested the possible sources. Particle size distribution suggested a median and mean diameter of particles counted was $0.24 \pm 0.02 \mu \mathrm{m}$ and $0.27 \pm 0.04 \mu \mathrm{m}$, respectively. The conclusion is that SEM methodology is a valuable tool for studying the distribution of particulate pollutants.
\end{abstract}

Keywords: PM10, biodiesel, environmental scanning electron microscope, particle size distribution, particle shape, morphology.

\section{INTRODUCTION}

In the past few decades, the significance of aerosols has been stressed many times. Many studies have looked at their influence on climate change through their contribution to radiative forcing [1]. It is well-known that aerosols directly affect climate through changes in the optical depth [2]. The morphology of atmospheric particles received significant importance in recent years due to the effect of the particles' shape on their radiative properties. Wang et al. [3] and Kalashnikova and Sokolik [4], for example, studied the role of the non-spherical shape of dust particles on their optical properties. The importance of the particles' shape affects the retrievals of aerosol optical properties from both satellite and ground-based remote sensing observations.

Atmospheric particle size distribution controls the rate of dry deposition (which determines the long-range transport of aerosols). Thus, the classification based on the aerosols' morphological characteristics - which is closely related to particle size - will give a better qualitative description of the atmospheric particles. The present analysis approach uses a similar particle size-and-shape technique which follows previous studies of aerosol particle properties [5].

There is evidence that exposure to PM from combustion sources, like traffic, impacts human health more severely than other PM [6-10]. This implies that the health effects associated with PM would relate best to anthropogenic emission sources [11, 12]. Pollutants are hazardous when released indoors because of the proximity of people and larger exposure time. Therefore, a bit of pollution released indoors is far more likely to reach a person's lungs than if released outdoors [13]. The estimates indicate that as many as 18,000 different combustion products may be adsorbed onto diesel

*Address correspondence to this author at the Civil Engineering Department, The University of Toledo, Toledo, Ohio 43606, USA; Tel: 419-5308136; Fax: 419-530-8116; E-mail: akumar@utoledo.edu particulates; therefore, the same can be assumed for biodiesel blends $[14,15]$. The toxicity of biodiesel exhaust has not been explored in detail. The sanitary limits, which encourage effective measures against prevailing health hazards, should be determined to permit the use of current engines.

In July 1997, the United States Environmental Protection Agency (US EPA) promulgated National Ambient Air Quality Standards (NAAQS) for fine PM [16]. The new standard is aimed at regulating ambient concentrations of $\mathrm{PM}_{10}$ and $\mathrm{PM}_{2.5}$ (particles with aerodynamic diameter $<10 \mu \mathrm{m}$ and $<$ $2.5 \mu \mathrm{m}$, respectively). $\mathrm{PM}_{10}$ comprises a broad range of primary and secondary particles dispersed throughout the atmosphere from a variety of sources. $\mathrm{PM}_{10}$ characteristics must be better understood to establish the relationship between anthropogenic emission sources and the indoor $\mathrm{PM}_{10}$ concentrations of public transport buses, a priority of the National Research Council [17].

Exposure to vehicular exhaust occurs within many different occupational groups, contributing to environmental air pollution. The concentration of different components in vehicular exhaust can vary depending on the composition of the propellant, contents of the motor oil, engineering of the motor, working temperature, load, and degree of wear, fuel supply, and condition of the motor [8, 18]. Studies have shown that the use of biodiesel blends does not have a significant effect on the mass of PM emission, although the physical and chemical properties of the PM are expected to change [19]. It is difficult to measure exhaust PM with simple air monitoring devices. It derives the need of major efforts to characterize the biodiesel exhaust emission in terms of PM. As such, understanding the physical and chemical characteristics of $\mathrm{PM}_{10}$ is needed to establish the relationship between public transport vehicle emission sources and indoor $\mathrm{PM}_{10}$ concentrations. In this way, the classification is based on the aerosols' morphological characteristics, which may lead to a better qualitative description of the suspended particles. 
These studies, coupled with the new NAAQS, have generated more interest in analytical techniques capable of measuring the size and morphology of individual aerosol particles. Several manufacturers and research organizations study refinements in biodiesel and aerosol technology. The SEM/EDS technique was developed in the late 1970s and early 1980s [20-22]. Numerous applications of SEM to environmental studies, aerosol characterization, and source apportionment have since been reported in the literature [15, 23-26]. Photomicrographs of individual particles can be obtained to present particle morphology data. Statistical methods or user-defined classification rules are used to sort particles into distinct particle classes to aid in source identification based on physical characteristics. Physical characterization of single particles can reveal source information, something that bulk chemical characterization, such as atomic absorption spectroscopy or x-ray fluorescence, can not reveal [25]. Physical characterization is therefore complementary to bulk elemental analysis techniques.

Moreover, SEM/EDS [27] technique uses electrons to provide magnified images, better feature resolution, wider range of magnification, and a greater depth-of-field than is available with the conventional light microscope [15]. The interaction of the electron beam and the sample produces different effects that should be monitored with suitable detectors. The resulting signals include secondary and backscattered electrons for imaging and characteristic $\mathrm{x}$-rays, which are used to determine elemental composition. The secondary, backscattered, and x-ray signals can be collected in synchronization with the position of the electron beam to provide the highly detailed spatial and compositional information of microscopic features. The spatial resolving power of the SEM technique is comparable on the submicron level, making it well-suited for $\mathrm{PM}_{10}$ analysis. Individual particle data offers the potential to more specifically identify and quantify $\mathrm{PM}_{10}$ sources that contribute to indoor or ambient air quality.

Previous studies focused on diesel exhaust emission and the use of multiple analytical techniques to assist in the characterization of $\mathrm{PM}_{10}$. This was done to gain a better understanding of the relationship between anthropogenic emission sources and natural $\mathrm{PM}_{10}$. Turrio-Baldassari et al. [28] reported the particle characteristics of biodiesel exhaust, but many studies described diesel particulates [15, 25, 26].
Solid particle phases are formed in diesel engines as a result of incomplete combustion in fuel-rich zones of the diffusion-controlled spray combustion. Patschull and Roth [29] reported particle charge and size distribution on diluted diesel exhaust obtained under different engine operation conditions using electrical mobility measurements. The particle number distribution measurements were carried out by a differential mobility particle size in a size range of 10-1000 $\mathrm{nm}$. Ensuring that the particles were spherical in shape proved to be a major limitation for the particle based studies. The calculation of the total mass concentration from the number distribution was also a major limitation in the previous studies [15].

Carpenter and Johnson [30] used transmission electron microscope (TEM) techniques to characterize the diesel PM. They described 24 samples from a diesel motor that runs according to a special running program, with respect to particle size, distribution, and appearance. The diluted diesel exhaust contained liquid hydrocarbons adsorbed on the solid particles. Contrary to expectations, size distribution did not differ between diluted and undiluted exhaust gases.

The study objective is to investigate SEM prospects to determine biodiesel fumes from indoor public bus environments, where the aerosol consists of both biodiesel fumes and dust particles from other pollutant sources. The paper presents characteristics of indoor particulates collected from the sampling in 2006-2008. Moreover, it discusses the application of electron microscopy in environmental studies for individual particle analysis using ESEM. First, results showing the SEM images from the indoor $\mathrm{PM}_{10}$ samples of a public bus fueled by biodiesel are reported. Second, the size and shape of the major particulate species are evaluated in the indoor environment of biodiesel buses running in Toledo, Ohio.

\section{METHODOLOGY}

Toledo Area Regional Transit Authority (TARTA) has over 40 routes in and around the Toledo metropolitan area, with an annual passenger mileage of approximately 22 million [31]. 180 buses run continuously, contributing to a significant percentage of the region's total particulate emissions. The particulate matter sample was collected inside the urban transit bus numbered 506, which was operated by TARTA, in the City of Toledo, on route number 20, as shown in Fig. (1).

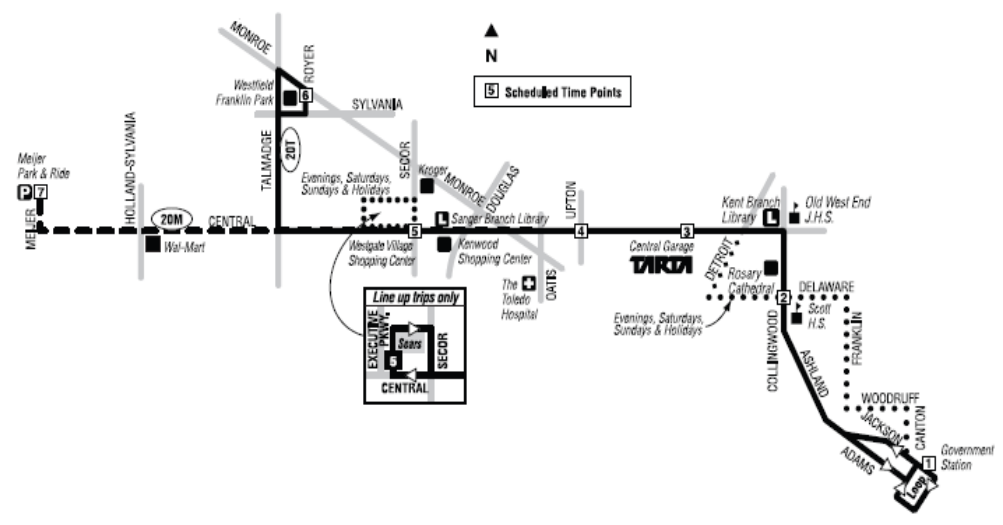

Fig. (1). Map showing Route \# 20 [31]. 
A Grimm Dust monitor 1.108 was used under $1.2 \mathrm{~L} / \mathrm{min}$ with the size range of $0.3-20 \mu \mathrm{m}$ (aerodynamic diameter) using $47 \mathrm{~mm}$ PTFE filters (Grimm Aerosol Technik GmbH $\&$ Co) with $0.3 \mu \mathrm{m}$ pores for the microscopic analysis. Eight collective daily samples from December, 2006 to June, 2007 were collected for the period of an ordinary day's condition inside an HVAC-equipped biodiesel-fueled bus. All the above samplings were conducted in a homogeneous environment inside the bus, and the sampling was continuous (except for six breaks) using the same filter. The samples were transported to the lab in a glass container supplied by SKC Inc. To avoid any contamination, filters were handled using gloves throughout the experiment. The samples were stored in a deep freezer before performing any analysis.

\section{SEM Analysis}

ESEM is used to analyze air particles. Since the technique is nondestructive, particles of interest can be relocated as needed. The environmental SEM micrograph permits the localization and analysis of individual particles in a large sample area without any coating treatment. Therefore, individual particle analysis was undertaken for morphology using ESEM. This analysis was carried out by using ESEM coupled with an automatic computer imaging system (having resolution $\sim 10 \mathrm{~nm}$ ).

The whole filter paper was mounted on a smooth $\mathrm{Cu}$ alloy stub for the SEM (scanning electron microscope) analysis. The instrument used was a SEM (Quanta 200 3D, FEI/Phillips, Germany) to obtain the morphology, size, and shape of individual particles. During the SEM detection, on each sample, around 100 particles were scanned and observed. The analytical settings for the automated particle analysis by ESEM used are listed below in Table $\mathbf{1}$.

Table 1. ESEM Parameters Used for the Analysis of the Filters

\begin{tabular}{|c|c|}
\hline \multicolumn{2}{|c|}{ ESEM } \\
\hline \hline Acceleration Voltage (KeV) & $10-30$ \\
\hline Magnification & $2000 \mathrm{x}$ \\
\hline Pressure & 0.9 Torr \\
\hline Spot Size & 4 \\
\hline Working Distance & $15 \mathrm{~mm}$ \\
\hline
\end{tabular}

\section{Particle Size and Shape Detection}

The particle size, morphology, and shape were included in the analysis. The particle size and shape analyzer (Particle Analysis Tab, Genesis Software, US) was used. Roughly 500 to 1,000 particles need to be characterized to get a representative sample [32], depending on the sample complexity and the overall research objectives. 35,377 particles were analyzed using automated x-ray and morphology data from discreet grayscale features. The filters were made ready for an electron microscopic investigation. For bus sample analyses, an ESEM with an image analyzer was used in the Electron Micro-beam Analysis Laboratory (University of Michigan, Ann Arbor, Michigan). A full filter paper was mounted on a bulk sample holder with silver adhesive. About 20 visual fields evenly distributed over the sample were analyzed at a 2000x magnification. The images from the ESEM were transmitted directly to an image analyzer, which measures the individual particles' diameter (D) and area. Interactive automatic measurement carried out the ESEM analysis. The threshold is defined as the brightness (grayscale) value in the digital imaging system selected by the operator to distinguish between particles and the filter background. The thresholds for particle detection and measurement are selected in such a manner to acquire data for as many features as possible. The threshold was self-correcting to report for the slight variation in image brightness from one analysis field to another one. It was made sure that the particles had a grayscale contrast from the background and were reasonably well- separated from each other. In order to avoid any edge effects, charging, and variable background intensity, the analysis was conducted in an environmental mode. The image collected in environmental mode showed better contrast between particles and background, and gray level thresholds were calibrated for consistency and reproducibility. The resolution was chosen based on the size of the particles and the magnification used for the analysis.

Line charts showing the distributions were drawn with the total area and volume for each class calculated. The counting and size distribution analysis was carried out on randomly selected observation fields. All particles within a field of view were counted with their diameter and area measured with the help of Genesis Software in real time with EDX. Tightly bound agglomerates were counted as single particles, while particle volumes were calculated from the area measurements by assuming the diameter as thickness. Secondary electron images were obtained for every particle and analysis field. The magnification for the single particle images was adjusted based on particle size. Since, $\mathrm{PM}_{10}$ characterization will require more detailed quantification, signal strength and particle volume are directly proportional to each other. Therefore, longer integration time is needed to analyze $\mathrm{PM}_{10}$.

\section{RESULTS AND DISCUSSION}

The analysis was based on 150 images, with most particles within the smallest size range (between 0.07 and $0.7 \mu \mathrm{m})$. Observed particles consisted of three dominant morphological types: large aggregates or clusters of spherules each approximately $60 \mathrm{~nm}$ in diameter; chains of spherules; and individual spherules. Our results agree with previous studies [33]. Transmission electron microscopy shows that diesel particles were mostly clusters of sub-micrometer spherical particles ranging from 7 to $120 \mathrm{~nm}$. Shi et al. [33] concluded that the differences between the studies reflected the differences in engine technology and fuel quality. The similar three morphological classes and irregular shapes were examined for B20 particles. For larger particles, the number concentration was less, and only a small number of particles with diameters greater than $4.5 \mu \mathrm{m}$ were found. Some micrographs of seven PM samples obtained by the ESEM method are shown in Fig. (2). All measurements were completed using these types of images.

Different particle morphologies found in the indoor air samples can be seen in the micrographs given in Fig. (2). All the sample types were found to have a large variety of parti- 


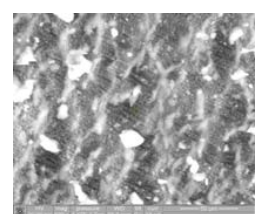

A

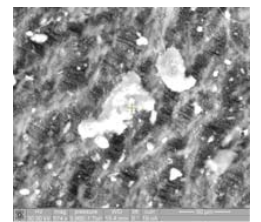

E
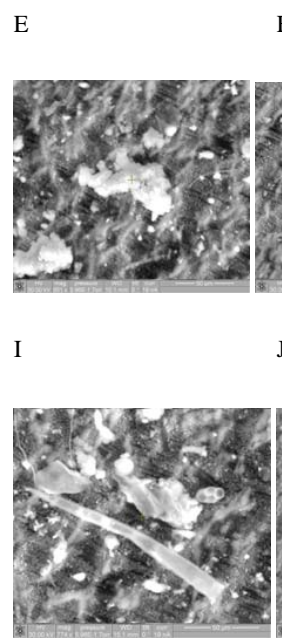

M

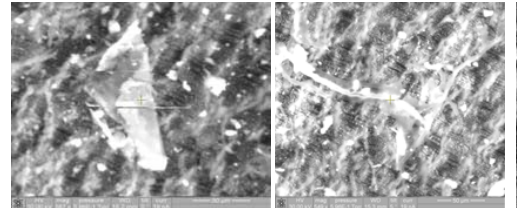

Q

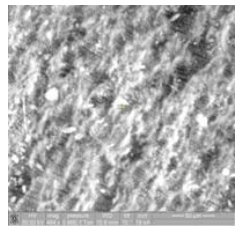

$\mathrm{U}$

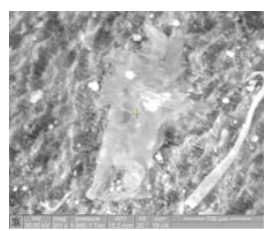

Y
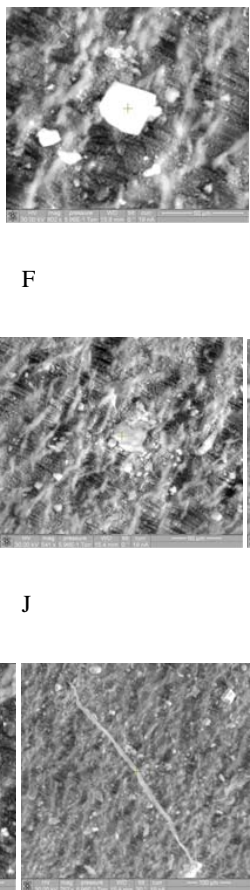
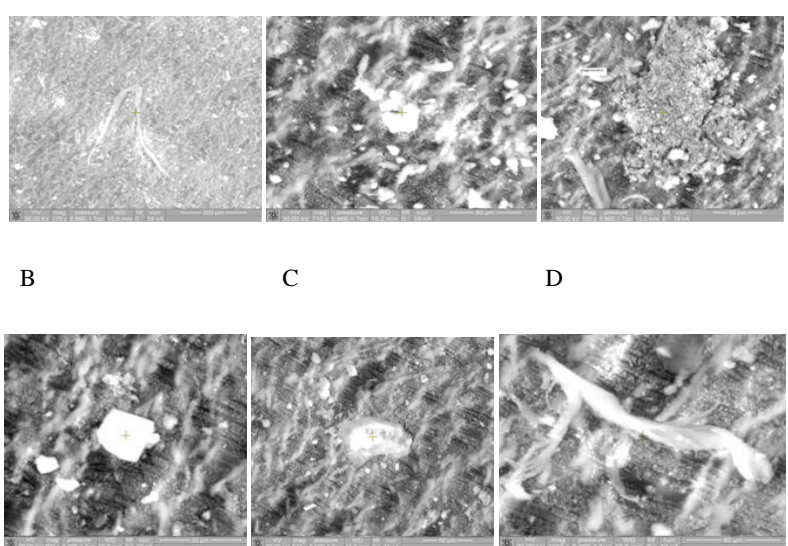

$\mathrm{H}$
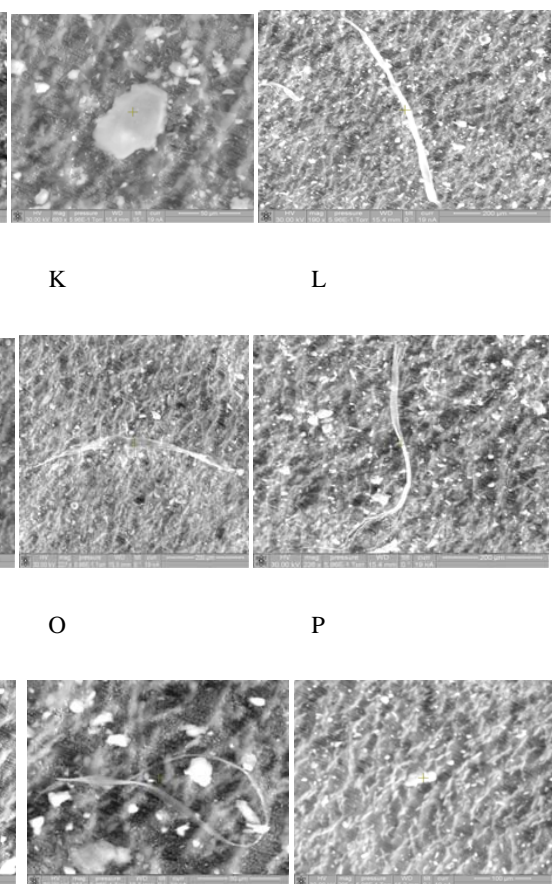

S

$\mathrm{T}$

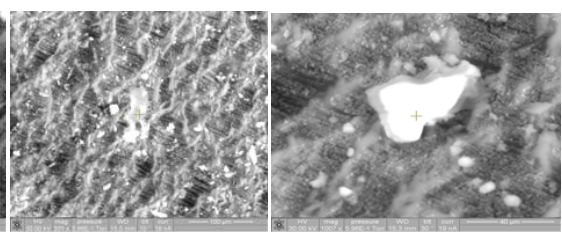

W

$\mathrm{X}$

Fig. (2). Scanning electron micrographs showing different particles. 
cles. By examining the species microstructure, it can be concluded that regular spherical symmetries were the prevailing structures and that these probably reflected the original shapes of the biodiesel particles inside the exhaust. Most of the images actually show the surface image of the particle. The particles differed in both morphology and size, and were in single and clustered forms. All the indoor air samples differed from each other with respect to the amount of crystalline and amorphous character that represent primarily mineral dust and biodiesel exhaust origin. Different categories of particle clusters observed in the present study can be described as needles with an uneven surface and several branches growing from the 'parent' needle (Fig. 2 H). They can also be described as needles (smooth surface) that are either curled (Fig. 2 B, O, S) or straight with branches (Fig. $2 \mathbf{H}, \mathbf{P}, \mathbf{V})$, with a specific orientation relative to the parent needle. Many particles had rough surfaces (Fig. 2 D, E, I). The particles from crust origin were also present characterized by their crystalline shapes (Fig. $2 \mathbf{Q}, \mathbf{X}$ ), which are described many times in the literature as glass-like structures.

Due to the depth of focus in the ESEM images, it is difficult to decide whether the parent needle and its branches are lying in, or coming out, of a plane normal to the incident electron beam. The apparent angle between a branch and its parent needle depends on their orientation relative to the plane, and may be either under- or over-estimated. The correct estimation can be achieved by tilting the sample around the ESEM axes. For a better image, both the needle and the branch have to obtain their maximum length parallel to the image plane. By following this procedure in the SEM, it was found that the branches grow with several random angles relative to the needle (Fig. $\mathbf{2} \mathbf{H}, \mathbf{V}$ ).

The projections shown in Fig. 2 (A, B, C, D, E, F, G, I, $\mathbf{L}, \mathbf{M}, \mathbf{O}, \mathbf{P}, \mathbf{Q}, \mathbf{S}, \mathbf{T}, \mathbf{V})$ are commonly seen when a single particle lies flat in the specimen holder, untilted in the SEM. The amorphous particles are suspected to mainly consist of carbon (Fig. D, E, I, J, K, Y). In contrast to the straight needles, the curled particles show no clear growth directions, but it can be argued that the particles can grow in random directions when they agglomerate. Fig. $2(\mathbf{H}, \mathbf{P}, \mathbf{R}, \mathbf{V})$ are the examples of particles that have grown-in zigzag, but are still similar to the straight particle needles. Investigation performed on the samples using SEM evidenced the presence of solid spherical particles with typical dimensions ranging between $200 \mathrm{~nm}$ and $2-3 \mu \mathrm{m}$. Acquired images will play a key role in the development of rules for particle classification. One important deficiency of the SEM characterization is the inability to explore the three-dimensional morphology of the particles and, therefore, assume that the investigated particles on the substrates are hemispherical.

Manual examinations indicate that the selected samples had adequately spaced particles, which were considered for determining particle size distribution. For each sample, more than 1,500 particles on several areas were measured. After compilation in a spreadsheet, the size data (diameter) were categorized and expressed as percentage totals. The total area and volume distribution for each class was calculated. The greater proportion of all particles was found to be in the sub $0.5 \mu \mathrm{m}$ diameter category. 35,647 particles from seven differ- ent samples were calculated. The median and mean diameters were $0.24 \pm 0.02 \mu \mathrm{m}$ and $0.27 \pm 0.04 \mu \mathrm{m}$, respectively.

The size distributions of the particulate are presented in this paper. The overall results summarized in line charts (Figs. 3 (a-c)) show the size distributions and the relative frequency of particle distributions in different size ranges (classes).

As established by many authors [22], the SEM method of analysis provides an intuitive way to identify a particular matter by its outlook. Fig. 3 (a and b) demonstrates both the possibilities and limitations of the SEM methodology for airborne particulate analysis originating from biodiesel exhaust. The airborne biodiesel particles are extremely small and occur either individually or in aggregation with the simultaneous presence of other diesel and dust particles. The particulates are composed of individual primary particles forming irregularly shaped chain-like agglomerations, as illustrated in Fig. 2 (I). If one determines particle area in classes using individual particle diameter, it appears that the aerosol consists of two modes: partly of a particle group with diameter $<0.8 \mu \mathrm{m}$, and partly of a group with diameter > $1.0 \mu \mathrm{m}$. The diameter range $0.8-1.0 \mu \mathrm{m}$ should be regarded as an interval with overlapping, as shown in Fig. (3). When calculating volume and then mass, biodiesel particles are found to constitute only a small share of the total dust weight. Although the conversion of volume to mass assumes particles as sphere, it strongly supports the above observation.

No diameter particle greater than $10 \mu \mathrm{m}$ was found in the samples. Thus it suggests that the GRIMM sampler used works properly with a cutoff diameter of $10 \mu \mathrm{m}$. The present study found a bi-modal distribution. The aerosol consists of the dust fraction $(1.0 \mu \mathrm{m})$ and the biodiesel exhaust or secondary fraction $(0.8 \mu \mathrm{m})$. The distinction of the size distribution inside the biodiesel fueled bus in two modules implies that one could define the size ranges important to exposure levels. Therefore, the size ranges below $1.0 \mu \mathrm{m}$ in diameter should be regulated. This does not mean that biodiesel exhaust agglomerates with a size greater than $1.0 \mu \mathrm{m}$ do not occur, but in the final particle concentration values, the effect will be minimal in characterization of biodiesel exhaust exposure levels. However, a certain standardization of the methodology is necessary. This includes the study of sampling time duration, analysis magnification, and sample load on the filters.

Biodiesel fume particles are extremely small. Some 95 percent of the particles are less than $0.3 \mu \mathrm{m}$. This means that direct display instruments do not function particularly well when sampling biodiesel fumes, and that the impact on the total mass from the small particles is extremely limited when comparing particles from other pollution sources. The gravimetric method should not, therefore, be recommended if one wants to understand or regulate occupational exposure for biodiesel exhaust. One should consider the number of particles rather than the mass concentration.

The crystalline nature of the particle's morphology suggests that it may have formed during post sampling from interaction with atmospheric gases, such as sulfur oxides and ammonia. SEM for the PM characterization requires an anal- 


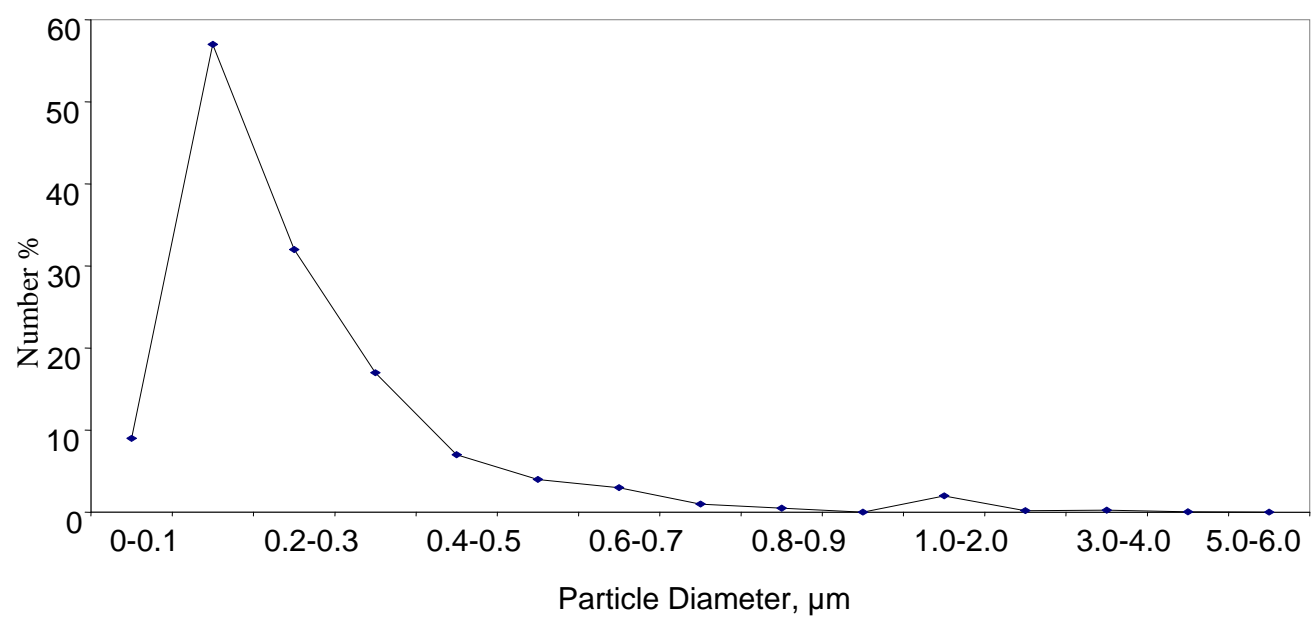

Fig. 3 (a) Number Distribution

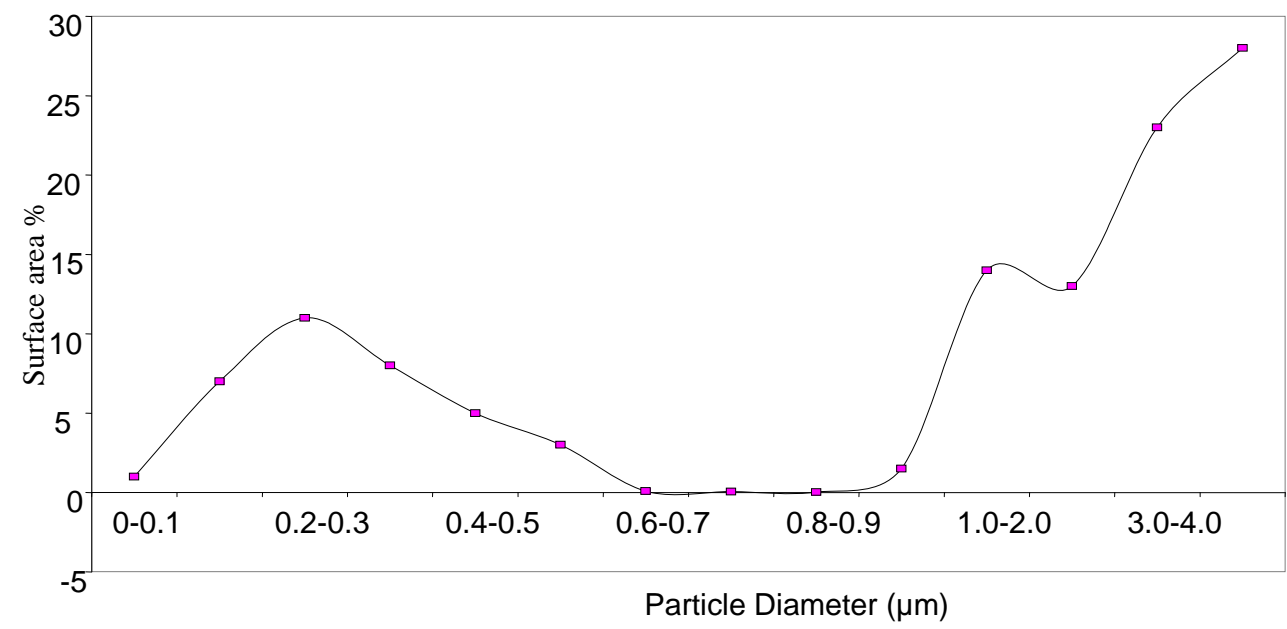

Fig. 3 (b) Surface Area Distribution

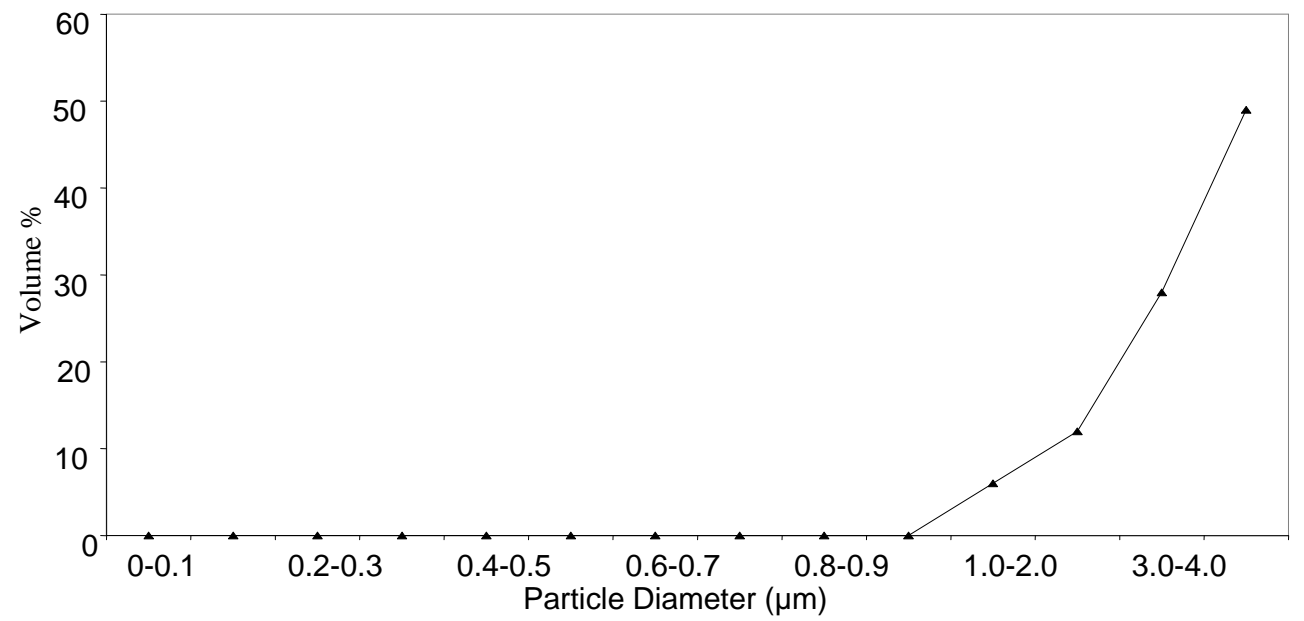

Fig. 3 (c) Volume Distribution

Fig. (3). Variations of (a) number distribution, (b) surface area distribution, and (c) volume with particle diameter. 
ysis of complex mixtures of fine PM. Among the $\mathrm{PM}_{10}$ is a relatively large agglomeration of fine particulate with chainlike morphology believed to consist of long chain hydrocarbons, perhaps from diesel emissions.

\section{CONCLUSION}

The paper summarizes the study results that will provide a basis for consideration of strategies to deal with the methodology for airborne biodiesel exhaust analysis in SEM. The study attempts to assess the opportunities and obstacles inherent in the methodology. The analysis method is sensitive to the amount of samples collected, and the sampling time determines the total PM collected on the filter. Therefore, standardization of sampling time is an important issue for future study.

One important deficiency of the SEM characterization is the inability to explore the three-dimensional morphology of the particles. By presenting a methodology and results dealing with indoor aerosols in public buses, the results of this study address the lack of published data on actual indoor aerosols by providing data on the particle characterization of extremely complex indoor aerosol in public buses. The need for more background data on aerosol characteristics, in particular the submicron aerosol, will lead the scientific community to expand and use the methods developed in this study to conduct further research into the nature of indoor and outdoor aerosols. The ESEM was used to characterize the morphology and microstructure of individual carbonaceous particles generated from diesel fuel. Such information, along with that obtained from other techniques, should be useful for evaluating the environmental and health impacts of carbonaceous particles produced by biodiesel combustion. Acquired images play a key role in the development of rules for particle classification.

Keywords: $\mathrm{PM}_{10}$, Biodiesel, Environmental Scanning Electron Microscope, Particle Size Distribution, Particle Shape, Morphology.

\section{ACKNOWLEDGEMENTS}

The authors would like to thank the Michigan-Ohio University Transit Consortium (MIOH-UTC), United States Department of Transportation (US DOT) and Toledo Area Regional Transit Authority (TARTA) for the alternate fuel grants awarded to the Intermodal Transportation Institute (ITI) of The University of Toledo. The authors would also like to express their sincere gratitude to the TARTA management and other employees for their continued interest and involvement in this work. The views expressed in this paper are those of the authors alone and do not represent the views of the funding organizations. The authors are also thankful to Electron Microbeam Analysis Laboratory (EMAL) facility of the Space Research Center at The University of Michigan for letting us use their facility for research.

\section{REFERENCES}

[1] J. Hansen, L. Nazarenko, "Soot climate forcing via snow and ice albedos", Proceedings of National Academy Of Sciences (PNAS), USA, vol. 101, pp. 423-428, 2004.

[2] V. Ramaswamy, O. Boucher, J. Haigh, D. Hauglustaine, J.M. Haywood, G. Myhre, T. Nakajima, G.Y. Shi, S. Solomon, "Radiative forcing of climate change" In: Climate Change 2001: The Sci- entific Basis. Contribution of Working Group I to the Third Assessment Report of the Intergovernmental Panel on Climate Change; J.T. Houghton, Y. Ding, D.J. Griggs, M. Noguer, P. van der Linden, X. Dai, K. Maskell, C.A. Johnson, Eds. UK: Cambridge University Press 2001; pp. 349-416.

[3] J. Wang, X. Liu, S.A. Christopher, J.S. Reid, E. Reid, and H. Maring, "The effects of non-sphericity on geostationary satellite retrievals of dust aerosols", Geophysical Research Letter, vol. 30, no. 24, p. 2293, 2003.

[4] O.V. Kalashnikova, I.N. Sokolik, "Importance of shapes and compositions of wind-blown dust particles for remote sensing at solar wavelengths", Geophysical Research Letter, vol. 29, No. 10, p. 1398, 2002.

[5] P.H. McMurry, X. Wang, K. Park, K. Ehara, "The relationship between mass and mobility for atmospheric particles: a new technique for measuring particle density", Aerosol Science Technology, vol. 36, pp. 227-238, 2000.

[6] K.K. Shandilya, M. Khare and A.B. Gupta, "Suspended particulate matter concentrations in commercial east Delhi and south Delhi, India", Indian Journal of Environmental Protection, vol. 26, no. 8, pp. 705-717, 2006.

[7] K.K. Shandilya, M. Khare and A.B. Gupta, "Suspended particulate matter concentrations in rural-industrial Satna and in urbanindustrial south Delhi”, Environmental Monitoring and Assessment, vol. 128, no. 1-3, pp. 431-45, 2007.

[8] A. Vijayan, A. Kumar, and M. A. Abraham, "Experimental analysis of vehicle operation parameters affecting emission behavior of public transport buses with alternative diesel fuels", Journal of the Transportation Research Board, vol. 2058, pp. 68-78, 2008.

[9] F. Laden, L. Neas, D. Dockery, J. Schwartz, "Association of fine particulate matter from different sources with daily mortality in six U.S. Cities", Environmental Health Perspective, vol. 108, pp. 941-947, 2000

[10] G. Hoek, K. Meliefste, J. Cyrys, M. Lewne, T. Bellander, M. Brauer, P. Fischer, U. Gehring, J. Heinrich, P. Van Vliet, B. Brunekreef, "Spatial variability of fine particle concentrations in three European areas", Atmospheric Environment, vol. 36, pp. 4077-4088, 2002.

[11] N. Kunzli, M. Jerrett, W.J. Mack, B. Beckerman, L. LaBree, F. Gilliland, D. Thomas, J. Peters, H.N. Hodis, "Ambient air pollution and atherosclerosis in Los Angeles", Environmental Health Perspectives, vol. 113, no. 2, pp. 201-206, 2005.

[12] A. Kadiyala, A. Kumar, "Application of CART and Minitab software to identify variables affecting indoor concentration levels", Environmental Progress, vol. 27, no. 2, pp. 160-168, 2008.

[13] D.W. Dockery, C.A. Pope, X.P. Xu, J.D. Spengler, J.H., Ware, M.E. Fay, B.G. Ferris, F.E. Speizer, "An association between air pollution and mortality in six U.S. cities", New England Journal of Medicine, vol. 329, pp. 1753-1759, 1993.

[14] K.K. Shandilya, A. Kumar, "Analysis of research studies on exhaust emission from the heavy duty diesel engine fueled by biodiesel", Handbook of Environmental Research, Ch. 2, A. Edelstein, D. Bars, Eds.; USA: Nova Science Publishers, Inc., 2009 (in press).

[15] K.K. Shandilya, "Characterization and Speciation of Fine Particulates in Ambient Air in Delhi", M.E. Thesis, Rajasthan University, Malaviya National Institute of Technology, Jaipur, India, 2002.

[16] U.S. Environmental Protection Agency, "National ambient air quality standards for particulate matter - final rule", 40 CFR part 50, Federal Register, vol. 62, no. 138, pp. 38651-38760, 1997.

[17] NRC, "Research priorities for airborne particulate matter-I: immediate priorities and a long-range research portfolio"; National Research Council, National Academy of Sciences, Washington DC, 1998, pp. 44-97.

[18] A. Kumar, V.V.K. Nerella, "Experimental analysis of exhaust emissions from transit buses fueled with biodiesel", Open Environmental Engineering Journal, vol. 2, pp. 81-96, 2009.

[19] A. Vijayan, "Characterization of Vehicular Exhaust Emissions and Indoor Air Quality of Public Transport Buses Operating on Alternative Diesel Fuels", Ph.D. Dissertation, The University of Toledo, Toledo, 2007.

[20] R.J. Lee, E.J. Fasiska, P. Janocko, D. McFarland, S. Penkala, "Electron-beam particulate analysis", Industrial Research and Development, vol. 21, pp. 25-28, 1979. 
[21] R.B. Hanna, K.J. Karcich, D.L. Johnson, "Determination of particle identities via a computer assisted SEM-EDXA system", Scanning Electron Microscopy, vol. 1, pp. 323-328, 1980.

[22] G.S. Casuccio, P.B. Janocko, R.J. Lee, J.F. Kelly, S.L. Dattner, J.S. Mgebroff, "The use of computer controlled scanning electron microscopy in environmental studies", J Air Pollution Control Association, vol. 33, pp. 937-943, 1983.

[23] D. Kim, P.K. Hopke, "Source apportionment of the El Paso aerosol by particle class balance analysis", Aerosol Science Technology, vol. 9, pp. 221-235, 1988.

[24] W. Jambers, R. Van Grieken, "Single particle characterization of inorganic suspension in Lake Baikal, Siberia", Environmental Science and Technology, vol. 31, pp. 1525-1533, 1997.

[25] K.K. Shandilya, A. Kumar, "Morphology of single inhalable particle inside public transit biodiesel fueled bus", Journal of Environmental Science, 2009 (in press) Abstract Available: http://www.jesc.ac.cn/jesc_en/ch/

reader/view_abstract.aspx?edit_id=20099310175634885\&journal_i d=jesc_en\&file_no $=200905045 \&$ flag $=2$.

[26] K.K. Shandilya, M. Khare and A.B. Gupta, "Defining aerosols by phy-sical and chemical characteristics", Indian Journal of Air Pollution and Control, vol. 9, no. 1, pp. 107-126, March 2009 Available Online: http:// www.scribd.com/doc/17224317/Final-SubmitAerosol-Paper.

[27] T.G. Dzubay, Y. Mamane, "Use of electron microscopy data in receptor models for PM-10”, Atmospheric Environment, vol. 23, pp. 467-476, 1989.
[28] L. Turrio-Baldassarri, C.L. Battistelli, L. Conti, R. Crebelli, B. De Berardis, A.L. Iamiceli, M. Gambino and S. Iannaccone, "Emission comparison of urban bus engine fuelled with diesel oil and biodiesel blend", Science of the Total Environnment, vol. 327, pp. 147162,2004

[29] J. Patschull and P. Roth, "Charge and size distribution of particles emitted from a diesel engine", Aerosol Science, vol. 23, no. S1, pp. S229-S232, 1992.

[30] K. Carpenter, J.H. Johnson, "Analysis of the Physical Characteristics of Diesel Particulate Matter Using Transmission Electron Microscope Techniques", In: Off-Highway Vehicle meeting and exposition, Document Number: 790812, SAE International Warrendale PA, 1979, pp. 10-13.

[31] Available from: http://www.tartabiodiesel.org/ [accessed 2007 onwards].

[32] Y. Mamane, R.D. Willis, T.L. Conner, "Evaluation of computercontrolled scanning electron microscopy applied to an ambient urban aerosol sample", Aerosol Science Technology, vol. 34, pp. 97-107, 2000.

[33] J.P. Shi, D. Mark, R.M. Harrison, "Characterization of particles from a current technology heavy-duty diesel engine", Environmental Science and Technology, vol. 34, pp. 748-755, 2000.

(c) Shandilya and Kumar; Licensee Bentham Open.

This is an open access article licensed under the terms of the Creative Commons Attribution Non-Commercial License (http://creativecommons.org/licenses/by-nc/3.0/) which permits unrestricted, non-commercial use, distribution and reproduction in any medium, provided the work is properly cited. 